\title{
Autoimmune serological studies in chronic gastritis and pernicious anaemia
}

\author{
IAN R. MACKAY ${ }^{1}$ \\ From the Clinical Research Unit of the Royal Melbourne Hospital and the \\ Walter and Eliza Hall Institute of Medical Research, \\ Melbourne, Victoria, Australia
}

EDITORIAL SYNOPSIS These serological observations provide further support for the concept of autoimmunization as an aetiological factor in these clinico-pathological conditions.

This paper describes the incidence of positive serological tests for autoantibodies to gastric mucosal antigen and to thyroglobulin in patients with chronic gastritis, pernicious anaemia, and postgastrectomy gastritis. The results support the recent concept (British Medical Journal, 1962) that diffuse atrophic gastritis, which is the essential lesion in most cases of pernicious anaemia, may have an autoimmune basis. The findings of an increased incidence of antithyroglobulin antibodies in patients with atrophic gastritis adds further evidence for the suggested association between chronic disease of the stomach and thyroid gland.

\section{METHODS}

Tests for complement-fixing antibodies to tissue extracts were performed as described by Gajdusek (1958); the gastric mucosal antigen was made up as a $10 \%$ saline extract of mucosa from the pars media of a freshly resected human stomach. Titres of 16 or greater were regarded as significantly positive. Antibodies to thyroglobulin were titrated by tanned red cell haemagglutination as described by Mackay and Perry (1960); titres of 100 or greater were regarded as significantly positive.

Chronic gastritis was diagnosed by histological examination of a blind biopsy specimen of gastric mucosa. The criteria for gastritis were glandular disorganization and atrophy with lymphocytic and plasma cell proliferation in the mucosa: however, lymphocytic proliferation was minimal in some of the advanced atrophic lesions of pernicious anaemia. The diagnostic criteria for pernicious anaemia were achlorhydria, atrophic gastritis, a megaloblastic bone marrow, a serum vitamin $B_{12}$ level of less than $100 \mu \mu \mathrm{g}$. per ml., and defective absorption of vitamin $B_{12}$.

${ }^{1}$ Working with the aid of a grant from the National Health and Medical Research Council of Australia.

\section{CASES STUDIED}

CHRONIC ATROPHIC GASTRITIS This group included 50 patients ( 16 males and 34 females) ranging in age from 31 to 83 years (average 61). This group included the subgroup of 30 patients with advanced gastritis reported in detail by Wood, Ralston, Ungar, and Cowling (1964) on page 27.

PERNICIOUS ANAEMIA This group included 42 patients (13 males and 29 females) ranging in age from 30 to 82 years (average 64 years).

POST-GASTRECTOMY SYNDROMES This group included 36 patients (18 males and 18 females) ranging in age from 32 to 77 years (average 55 years); all were under investigation for various post-gastrectomy syndromes including post-prandial discomfort, dyspepsia, vomiting, malabsorption and anaemia, and many had histologically demonstrable gastritis.

CONTROL SUBJECTS These were randomly selected blood donors of both sexes and all were aged less than 60 years: this group was younger than the preceding groups of patients.

\section{RESULTS}

The results of tests for autoantibodies in the four categories of patients are presented in Table $I$ and Figures 1 and 2.

Positive complement-fixation reactions with gastric mucosal antigen, to a titre 16 or greater, were obtained in $28 \%$ of the 50 patients with chronic gastritis, in $31 \%$ of the 42 patients with pernicious anaemia, in $14 \%$ of 36 patients with post-gastrectomy syndromes, and in $2 \%$ of healthy controls. The fact 
TABLE I

INCIDENCE OF SEROLOGICAL REACTIVITY TO GASTRIC MUCOSAL ANTIGEN, LIVER ANTIGEN, AND THYROGLOBULIN IN PATIENTS WITH GASTRIC DISEASE

\begin{tabular}{|c|c|c|c|c|c|c|c|c|c|c|}
\hline \multirow[t]{3}{*}{ Diagnosis } & \multirow[t]{3}{*}{ Total Cases } & \multicolumn{9}{|c|}{ Antigens } \\
\hline & & \multicolumn{3}{|c|}{$\begin{array}{l}\text { Gastric Mucosa } \\
\text { Titres }\end{array}$} & \multicolumn{3}{|c|}{$\begin{array}{l}\text { Liver } \\
\text { Titres }\end{array}$} & \multicolumn{3}{|c|}{$\begin{array}{l}\text { Thyroglobulin } \\
\text { Titres }\end{array}$} \\
\hline & & $<4$ & $4-8$ & $\begin{array}{r}16 \\
>16\end{array}$ & $<4$ & $4-8$ & $\begin{array}{r}16 \\
>16\end{array}$ & $<20$ & $20-100$ & $>100$ \\
\hline $\begin{array}{l}\text { Atrophic gastritis } \\
\text { Pre-pernicious anaemia } \\
\text { Pernicious anaemia } \\
\text { Post-gastrectomy } \\
\text { Normal controls }\end{array}$ & $\begin{array}{l}50 \\
29 \\
42 \\
36\end{array}$ & $\begin{array}{l}24 \\
12 \\
17 \\
22 \\
45\end{array}$ & $\begin{array}{r}12 \\
10 \\
12 \\
9 \\
4\end{array}$ & $\begin{array}{c}14(28 \%) \\
7(24 \%) \\
13(31 \%) \\
5(14 \%) \\
1(2 \%)\end{array}$ & $\begin{array}{r}44 \\
26 \\
36 \\
33 \\
306\end{array}$ & $\begin{array}{r}6 \\
3 \\
6 \\
2 \\
13\end{array}$ & $\begin{array}{l}0 \\
0 \\
0 \\
1(3 \% \\
11(3 \%\end{array}$ & $\begin{array}{r}33 \\
21 \\
21 \\
21 \\
153\end{array}$ & $\begin{array}{l}5 \\
1 \\
8 \\
5 \\
8\end{array}$ & $\begin{array}{r}12(24 \%) \\
7(24 \%) \\
13(31 \%) \\
10(28 \%) \\
7(4 \%)\end{array}$ \\
\hline
\end{tabular}

that complement-fixation tests with liver antigen were mostly negative in the patients under consideration indicated that a stomach specific antigen was probably concerned in these reactions. The incidence of positive reactions to gastric mucosal antigen in patients with pernicious anaemia in the present series was lower than the incidence reported by others, as shown in Figure 1.

The incidence of positive tanned red cell haemagglutination tests for thyroglobulin antibody was similar for the three groups of patients in the

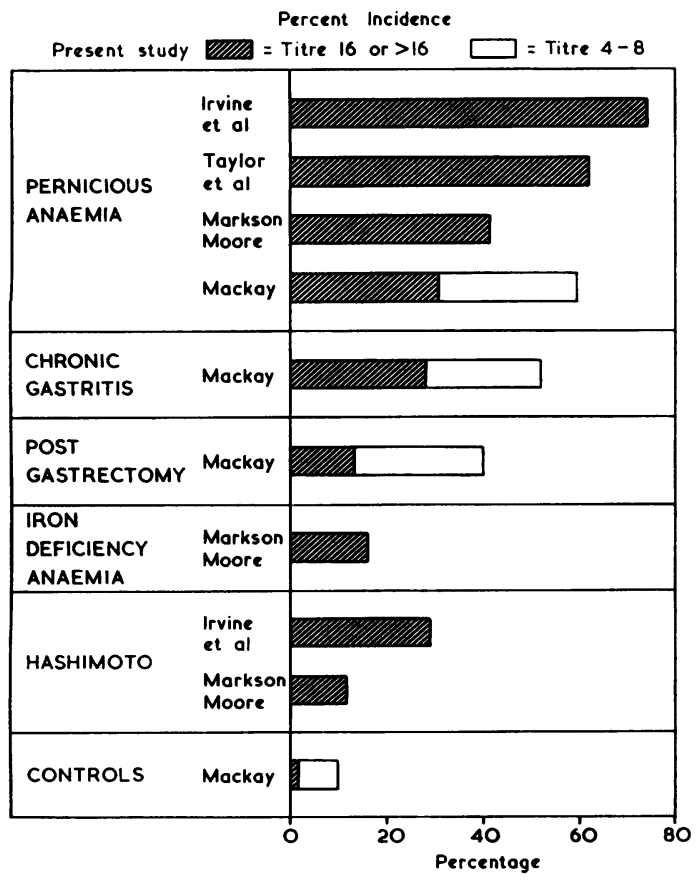

FIG. 1. Incidence of complement-fixing antibodies to gastric mucosa in pernicious anaemia, chronic gastritis, and other conditions: findings in present study compared with those of others. present series, ranging from $24 \%$ to $31 \%$; the incidence of $28 \%$ in post-gastrectomy subjects was unexpectedly high. Most of the positive reactions with thyroglobulin were in the range of titre of 100 to 1,000 , but a few patients in each group reacted to a very high titre.

The subgroup of patients, studied in detail by Wood, Ralston, Ungar, and Cowling (vide supra), with advanced chronic atrophic gastritis (prepernicious anaemia) was considered separately (Table I). It will be noted that their incidence of positive reactions with gastric and thyroid antigen did not differ significantly from that of the chronic gastritis group as a whole nor from that of the pernicious anaemia group.

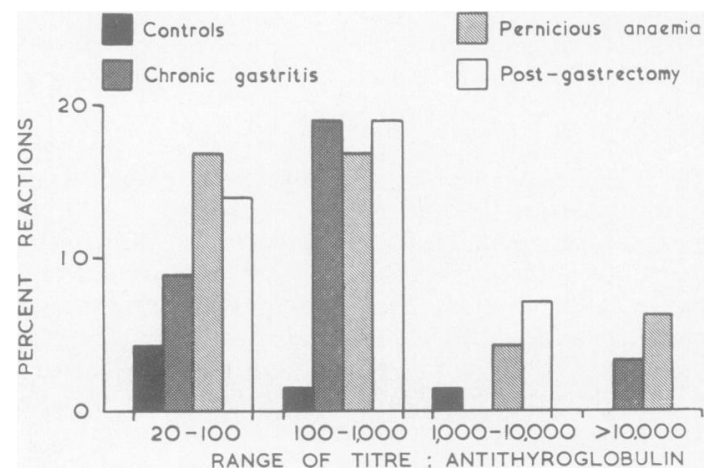

FIG. 2. Incidence of antithyroglobulin antibody in control subjects and in cases of chronic gastritis, pernicious anaemia, and post-gastrectomy syndromes.

\section{DISCUSSION}

The concept that autoimmunization might be implicated in the pathogenesis of pernicious anaemia arose from observations by Schwartz $(1958 ; 1960)$ and Taylor (1959) on anti-intrinsic factor activity of the serum of patients with pernicious anaemia. 
Further confirmation of this property of pernicious anaemia sera was presented by Jeffries, Hoskins, and Sleisenger (1962) and by Taylor, Roitt, Doniach, Couchman, and Shapland (1962).

The finding in the present study of a complementfixing autoantibody to a gastric mucosal antigen in the serum of patients with pernicious anaemia is in keeping with the findings of Irvine, Davies, Delamore, and Williams (1962), Markson and Moore (1962a), and Taylor and co-workers (1962). Moreover, our finding of a similar incidence of positive reactions in chronic gastritis and pernicious anaemia is consistent with the generally held view that the gastric lesion of pernicious anaemia is merely a late stage of a slowly evolving chronic gastritis. All of our post-gastrectomy patients had post-operative disability and/or histologically demonstrable gastritis, but nevertheless the incidence of positive reactions to stomach antigen $(14 \%)$ and to thyroglobulin $(28 \%)$ will require confirmation by study of a larger series of patients, with an analysis according to the antecedent lesion, indication for the gastrectomy, the nature of subsequent symptoms, and the age of the patients.

The fact that a proportion of sera in all reported pernicious anaemia series fail to react to gastric mucosal antigen could be attributed to relative insensitivity of the techniques employed, since the more sensitive immunofluorescence technique used by Taylor and co-workers (1962) gave positive results in $86 \%$ of sera. Another possibility, considered by Jeffries et al. (1962), is that there is 'antigenic exhaustion' in the advanced gastric lesion of long-standing pernicious anaemia; the present study did not favour this possibility since patients with chronic gastritis in the pre-pernicious anaemia stage did not show a higher incidence of reactions with gastric mucosa than did patients with fully developed pernicious anaemia.

It is repeatedly emphasized that the serological demonstration of autoantibodies cannot in itself be taken as proof of autoimmune disease, and collateral evidence must be sought to substantiate autoimmunization as a specific pathogenic mechanism in any particular disease process. One point is that the dense lymphocytic and plasma cell infiltration, associated with structural disorganization of the gastric mucosal parenchyma, in chronic gastritis is analogous to the histopathological changes of autoimmune damage in other tissues. A third line of evidence is the undoubted connexion between chronic thyroiditis and pernicious anaemia, as revealed by the coexistence of these two conditions and the serological overlap between them. Furthermore it is established that in pernicious anaemia prednisolone will induce a haematological response and will increase vitamin $B_{12}$ absorption; ØstergaardKristensen and Friis (1960) suggested that prednisolone may exert this action by inhibiting an autoimmune process.

Tudhope and Wilson $(1960 ; 1962)$, in a study on 73 patients with spontaneous hypothyroidism, found that nine $(12.3 \%)$ had pernicious anaemia and an additional seven had 'extensive deficiency of vitamin $\mathbf{B}_{12}$ without pernicious anaemia'; they concluded that there could be 'a common factor tending to produce destruction both of the thyroid gland and of the gastric mucosa', and inferred that autoimmunization might represent this factor. Williams and Doniach (1962) formed a similar opinion on the basis of their necropsy study wherein they found an unexpectedly high incidence of thyroiditis in patients with pernicious anaemia. It will be of particular interest to see whether the suggested association between thyrotoxicosis and pernicious anaemia (Tudhope and Wilson, 1960; McNicol, 1961) can be confirmed. The clinical and pathological evidence linking pernicious anaemia and thyroiditis is substantiated by the serological overlap between the two conditions. First, there is a significantly raised incidence of anti-thyroid antibodies in pernicious anaemia, figures of $24 \%, 37 \%$, and $31 \%$ being obtained by Markson and Moore (1962b), Irvine and co-workers (1962), and in this study respectively. Secondly there is a correspondingly increased incidence of antibodies to gastric mucosa in Hashimoto's thyroiditis, as shown by Irvine's group (1962) and by Markson and Moore (1962a).

The 'autoimmune' serological findings in patients with pernicious anaemia and gastritis present further opportunities for investigation. The nature of the gastric antigen concerned in the complementfixation reaction with pernicious anaemia sera, shown by Taylor and co-workers (1962) to be located in the cytoplasm of parietal cells, is still to be identified. The significance of high titre antithyroid reactions in pernicious anaemia sera is being studied in our Unit by thyroid biopsy, which has shown a range of changes frequently characterized by varying degrees of lymphoid hyperplasia (see Burnet and Mackay, 1962). Finally it will be of interest to correlate the autoimmune concept with the fact that there is clear genetic predisposition to the underlying gastric lesion of pernicious anaemia (Callender and Denborough, 1957). This genetic predisposition to a specific type of autoimmune process has analogies in regard to systemic lupus erythematosus (Pollak, Mandema, and Kark, 1960) and thyroiditis (Hall, Owen, and Smart, 1960), and also in regard to autoimmune haemolytic anaemia in the isogenic strain of NZB/BL mice now 
being studied in Dunedin and Melbourne (Burnet, 1962).

\section{SUMMARY}

Autoantibodies to human gastric mucosal antigen, to a titre of 16 or greater, were found in $28 \%$ of patients with chronic atrophic gastritis and in $31 \%$ of patients with pernicious anaemia, and antibodies to thyroglobulin, to a titre of $>100$, were found in $24 \%$ and $31 \%$ of such patients respectively. There was also an increased incidence of autoimmune serological reactions in patients with post-gastrectomy syndromes. The present serological findings in chronic gastritis and pernicious anaemia, which are comparable with data reported by others, provide further support for the concept of autoimmunization in these conditions.

I am indebted to Miss Sue La Gerche and Miss Glenys Almond for laboratory assistance.

\section{REFERENCES}

British Medical Journal, Editorial. (1962). New light on pernicious anaemia. Brit. med. J., 2, 1379-1380.

Burnet, Sir M. (1962). Autoimmune disease-experimental and clinical. Proc. roy. Soc. Med., 55, 619-626.

autoimmune disease. Lancet, 2, 1030-1033.

Callender, S. T., and Denborough, M. A. (1957). A family study of pernicious anaemia. Brit. J. Haemat., 3, 88-106.

Gajdusek, D. C. (1958). An 'autoimmune' reaction against human tissue antigens in certain acute and chronic diseases. I. Serological investigations. Arch. intern. Med., 101, 9-29.
Hall, R., Owen, S. G., and Smart, G. A. (1960). Evidence for genetic predisposition to formation of thyroid autoantibodies. Lancet, 2, 187-188.

Irvine, W. J., Davies, S. H., Delamore, I. W., and Williams, A. W. (1962). Immunological relationship between pernicious anaemia and thyroid disease. Brit. med. J., 2, 454-456.

Jeffries, G. H., Hoskins, D. W., and Sleisenger, M. H. (1962). Antibody to intrinsic factor in serum from patients with pernicious anemia. J. clin. Invest., 41, 1106-1115.

Mackay, I. R., and Perry, B. T. (1960). Autoimmunity in human thyroid disease. Aust. Ann. Med., 9, 84-92.

McNicol, G. P. (1961). Thyrotoxicosis associated with pernicious anemia. Amer. J. med. Sci., 241, 336-342.

Markson, J. L., and Moore, J. M. (1962a). Autoimmunity in pernicious anaemia and iron-deficiency anaemia. Lancet, 2, 1240-1243.

_Brit. med. J., 2, 1352-1355.

Østergaard-Kristensen, H. P., and Friis, T. (1960). The mechanism of the prednisone effect upon $B_{19}$ absorption in pernicious anaemia. Acta med. scand., 168, 457-459.

Pollak, V. E., Mandema, E., and Kark, R. M. (1960). Antinuclear factors in the serum of relatives of patients with systemic lupus erythematosus. Lancet, 2, 1061-1063.

Schwartz, M. (1958). Intrinsic-factor-inhibiting substance in serum of orally treated patients with pernicious anaemia. Ibid., 2, 61-62.

- (1960). Intrinsic factor antibody in serum from patients with pernicious anaemia. Ibid., 2, 1263-1267.

Taylor, K. B. (1959). Inhibition of intrinsic factor by pernicious anaemia sera. Ibid., 2, 106-108.

_-, Roitt, I. M., Doniach, D., Couchman, K. G., and Shapland, C. (1962). Autoimmune phenomena in pernicious anaemia: gastric antibodies. Brit. med. J., 2, 1347-1352.

Tudhope, G. R., and Wilson, G. M. (1960). Anaemia in hypothyroidism. Quart. J. Med., 29, 513-537.

-, . (1962). Deficiency of vitamin $B_{12}$ in hypothyroidism. Lancet, 1, 703-706.

Williams, E. D., and Doniach, I. (1962). The post-mortem incidence of focal thyroiditis. J. Path. Bact., 83, 255-264.

Wood, I. J., Ralston, M., Ungar, B., and Cowling, D. C. (1964). Vitamin $B_{12}$ deficiency in chronic gastritis. Gut, 5, 27. 